\title{
On the optimal timing of the oil pollution act: Is there more value in waiting than acting?
}

\section{George Dikos*}

Supply Chain Optimization and Planning, Lafarge Cement, P.O. Box 65582,

15402 Neo Psychiko, Athens, Greece

E-mail: Dikosg@aget.gr

${ }^{*}$ Corresponding author

\section{Sgouris P. Sgouridis}

Massachusetts Institute of Technology, Engineering Systems Division, USA

E-mail: sgouris@mit.edu

\begin{abstract}
Following the Exxon-Valdez incident the, Oil Pollution Act was enacted by the US government in 1990 mandating double hull construction tankers operating in US coastal tankers. Traditional Cost Benefit Analysis to investigate whether this requirement is cost efficient does not include the timing of the implementation in anticipation of technological improvements or other system changes. We investigate the option value of waiting by applying the standard model for optimal timing of environmental policy (Pindyck, 2002) and extend it to accommodate irregular and extreme emissions. We demonstrate that neglecting the occurrence of extreme events can be misleading.
\end{abstract}

Keywords: tanker industry; real options; environmental policy.

Reference to this paper should be made as follows: Dikos, G. and Sgouridis, S.P. (2008) 'On the optimal timing of the oil pollution act: Is there more value in waiting than acting?', Int. J. Ocean Systems Management, Vol. 1, No. 1, pp.100-117.

Biographical notes: George Dikos holds an SM in Shipping, Trade and Finance from Cass University Business School and an SM and PhD in Ocean Systems Management from MIT. He has been an Associate Visiting Professor at the Frederick University in Cyprus and a Lecturer at the University of Patras. He has worked as Project Manager for RayCap Corporation and is currently running Supply Chain Optimization and Planning for Lafarge Cement in Greece. He has consulted regularly for the shipping industry and has published several papers in Maritime Economics and Management Science.

Sgouris P. Sgouridis holds an MSc in Technology and Policy and MSc in Transportation from MIT and a PhD in Technology, Management and Policy from the Engineering Systems Division of MIT. He is currently an Assistant Professor in Engineering Systems and Management at the Masdar Institute of Science and Technology, Abu-Dhabi UAE. His interests include commercial aviation, sustainability and environmental impacts of transport. 


\section{Introduction}

\subsection{Double hull phase-in in the maritime industry: the effects of sunk cost and uncertainty}

Economic advice to regulators regarding the adoption of policies in response to a perceived threat to the environment depends, to a certain extent, on an economic evaluation of the consequences. The traditional cost-benefit analysis is comparatively disadvantaged in evaluating outcomes with significant uncertainty (Wang and deNeufville, 2005) as is the case of environmental degradation. Pindyck $(2000,2002)$ proposed a methodology for assessing environmental impacts of pollutant emissions. His methodology is best suited to problems where a constant stream of pollutants is emitted to the environment. We propose a framework for estimating the mistakes by foregoing the associated option value of waiting and show that for cases that are characterised by rare pollution events with extreme consequences, as is the case of oil-spills from tanker accidents, a variant on this approach is needed. Both ecological damages and capital investments to prevent them have the potential to impose sunk costs on society. Under uncertainty and irreversibility it may be preferable to time regulatory responses based on information about potential ecological impacts, economic consequences, and prospective technical innovation. The value of waiting depends on the severity and irreversibility of the environmental damage under consideration as well as the potential effectiveness of proposed actions.

Recently, option theory has been important for economics and investment decisions. After the introduction of the 'real option' value, implicit in investment decisions (McDonald and Siegel, 1984), it has been well understood that uncertainty has a key role in investment. Under uncertainty and irreversibility (Dixit and Pindyck, 1994, p.142) the Net Present Value rule is incorrect for evaluating investment decisions; uncertainty and irreversibility drive a wedge between the critical value of the project and the direct or tangible cost of investment. The results regarding the value of real options may be easily extended to the design and implementation of policy intervention. Dixit and Pindyck (1994) and Pindyck (2002) discuss the relevance of the real option approach to environmental policy design: Hausman and Myers (2002) apply the real options framework and discuss the effects of sunk costs and asymmetric risks on price regulations in the railroad industry. They demonstrate how large mistakes can be, when foregoing the effect of sunk costs and irreversibility in policy design.

As discussed by Dixit and Pindyck (1994) the standard framework that recommends a policy if the present value of the expected flow of costs is less than the expected flow of benefits ignores three important characteristics of most environmental problems. First, there is uncertainty over the cost and benefits of specific policies. Second there are irreversible investments associated to certain policies, such as the mandatory phase out of a class of vessels in the tanker industry, discussed in this paper. Thirdly, by imposing a rigid regulation, legislators forego their option to wait, collect additional information and encourage technological innovation. Therefore the inappropriateness of the net present value rule under uncertainty and irreversibility is similar to the inappropriateness of the cost benefit analysis rule under sunk costs and uncertainty, which is essential for policy evaluation.

A recent example on the adoption of an irreversible environmental policy with sunk costs, uncertainty and asymmetries occurred in the tanker industry. Ma (2002) offers 
an excellent review of the economics of maritime safety and environment regulations. According to Ma (2002, pp.417, 418), maritime transport related problems are mainly related to accidents. Due to the accidental nature of pollution in this industry, the emission permit system is not directly relevant to our analysis. However it can accommodate some important facts regarding the effects of uncertainty on environmental policy design. In the wake of the tanker Exxon Valdez accident, where 11-30 million gallons of crude oil were spilled, it was concluded that all tankers operating in US waters should have a double skin. According to Brown and Savage (1997) this increases capital and operating costs significantly, foregoes the value of waiting and induces a significant level of uncertainty regarding the (projected) economic benefits. Furthermore, it induces significant uncertainty on the long-term effects of the policy on the life time of the vessels.

The national and international legislation that imposes the phase-in of double hull oil tankers may eventually improve the safety record of the shipping industry, but it foregoes the option to wait before committing to an irreversible policy with significant uncertainties and sunk costs. The contribution of the paper is twofold: Firstly a relevant framework is introduced for estimating the mistakes by foregoing the associated option value of waiting with regards to a specific policy question. Secondly, the model is extended to accommodate the specific characteristics (accident type) of the nature of environmental damage in this industry. The policy implications are bidirectional:

On the one hand policy regulators should be cautious when applying cost-benefit analysis under uncertainty and irreversibility. On the other hand, real option models of environmental policy can be misleading, if the pollutant stock is caused by irregular changes and extreme events (jumps).

In this paper we combine the optimal design framework for policy evaluation introduced by Pindyck (2002) and the results regarding the importance of sunk costs and uncertainty on policy by Hausman and Meyers (2002) in the problem of evaluating the new technology imposed by the need for environmental measures under an economic perspective. In Section 2 we overview the relevant regulatory actions taken for phasing-in the double-hull standard as a measure to decrease the probability and severity of accidental oil spill. Furthermore, we discuss the impact of the technology on factors that determine the economics of this industry. Section 3 introduces the real options perspective as a method to inform regulatory policy in a way that takes into account uncertainty and the value of regulatory options. The Pindyck (2002) framework is applied to the problem at hand and presents a preliminary attempt in modelling the issue with realistic parameters. In Section 4 we extend the standard model for the optimal timing of environmental policy (Pindyck, 2002) in order to accommodate irregular changes. Neglecting the occurrence of jumps can be misleading as policy should then be undertaken earlier. Finally, in Section 5 we review the implications of the model.

\section{Double-hull tanker phase-in: background and implications}

The majority of the world's needs in oil and its derivatives are covered through sea transportation. Tankers hull designs have remained fundamentally the same consisting of a thin metal shell ${ }^{1}$ supported by a beam structure. Unfortunately using this design for tankers has the significant disadvantage of separating oil and the environment by only a thin covering sheet. Although it is estimated that $99.995 \%$ of the oil shipped by sea 
reaches safely at its destination (Gold, 1991), the rest of the percentage is enough to cause environmental disasters due to breaching of this shell since sea accidents caused by collisions or groundings are unavoidable. The percentage amount of oil spilled into the sea because of accidents is estimated to be $30 \%$ of the total, with the rest coming from normal operations (National Research Council, 1985). On the other hand, only 3\% of the accidents account for $95 \%$ of the total oil spilled by accidents.

Consequently, the nature of these incidents is catastrophic resulting firstly in the deterioration of pristine environments and in huge clean-up efforts and secondly in public outcry and increased regulatory efforts. From a policy perspective, due to the accidental nature of maritime pollution, the emission permit system has limited applicability in this market (Ma, 2002). Subsequently, the governments and international organisations have regulated the phase-in of a tanker design that is supposed to offer greater protection against environmental pollution: the double-hull. ${ }^{2}$

This paper proposes a real options framework for evaluating this decision and argues that the technology forcing potential of the US regulations (and of the European Union (EU) in a lesser degree) is limited, since they prescribe one technological standard or fix, which is far from fault-free. By departing from the technical nature of the problem and focusing on the economic consequences under uncertainty and irreversibility, we introduce a framework for estimating the mistakes by foregoing the associated option value of waiting. Acknowledging that the problem at hand is multifaceted and with global implications, an in depth presentation of the relevant parameters follows in Section 3, within the framework of the optimal timing problem. In this section, we briefly discuss the salient characteristics of the oil shipping industry, the regulations promulgated by the international community, and their technological assumptions and implications, which will provide the necessary insight into the structural interpretation of the parameters of the model and highlight the complexity of the problem.

\subsection{The tanker industry}

The oil tanker industry is an example of almost perfect competition. As discussed by Strandenes (2002, p.186) there are remote limits to entry in the tanker market industry. Information is publicly available to all investors in this market and the cost of exiting is fairly low. Organised shipbrokers operate in markets for ships they collect data and information and take care of the allocation to agents in this industry. All these characteristics indicate a well functioning market. This has a profound impact, as it does not raise any issues of strategic behaviour, once the policy is introduced.

Owners have the option to exit the market by selling their vessel for scrap or by selling it in the market for second hand vessels. Besides the active second hand market, an organised market for future and forward contracts exists. The latter guarantees the existence of a set of spanning assets that allows owners to span uncertainty in this market, which is an essential prerequisite for any real option model. Tanker freight rates determine the revenue a ship earns for servicing a particular contract for a pre-specified period of time and vary with duration and vessel type. They are fairly standardised, quoted in terms of US dollars per day and the market for one-year time charter contracts is well organised and relatively liquid. Time charter rates are paid to the owner of the vessel, who is then liable for the operating expenses (crew, insurance, etc.), as voyage costs, such as fuel, port fees and canal tolls, are paid by the charterer. The difference between rates and operating costs determines the earnings before taxes, interest and 
depreciation. Overall, international oil shipping (and shipping in general) is a competitive and open market. Pricing for both shipping of goods as well as vessels are greatly influenced by the vitality of global economy. The major ship construction has been transferred from the Western economies to the East in a successful case of technological diffusion. Now the major shipyards are in S. Korea, China and to a lesser extent Japan. They follow a supply-driven policy, constructing vessels sometimes even before orders are put, which makes the prices of new vessels more prone to fluctuation. As a result the vessels, as the main assets of the shipping industry, have volatile economic depreciation rates and the shipping companies do not have the incentive to invest in very high quality ships or to scrap marginally seaworthy vessels. In addition to the above, over investment and subsidisation have resulted in pricing policies by shipyards that do not respond to real economic conditions (Dikos, 2004a). In addition, this has lead producers of vessels to low cost and low quality constructions. Subsidisation and fierce competition among constructors will have profound implications on the long-term effects of the forthcoming policy. Producers will 'shave the rules' (Devanney and Kennedy, 2003) and reduce standards, with negative effects on the technical quality of new ships and the level of standards. This is essential for understanding the significant risks due to the new policy. Finally, several side effects of the double hull policy will impact the economic life time and classification evaluation of vessels. All the above generate uncertainty regarding the effectiveness of the policy, as no prior information exists.

\subsection{Relevant legislature}

The legislative framework that is setting the stage for the discussion is outlined in this section. This is necessary for understanding the irreversible nature of the policy. It is easily noted that the timing of each new regulatory efforts on the oil spill prevention front follows major oil spill incidents with great public involvement. A road map of regulation-invoking incidents can be seen in Table $1 .^{3}$

Table 1 Major incidents and ensuring legislations

\begin{tabular}{llccl}
\hline \multirow{2}{*}{ Ship name } & Location & Year & $\begin{array}{c}\text { Oil spilled in 1000 } \\
\text { barrels }\end{array}$ & Relevant regulation \\
\hline Torry Canyon & Wales, UK & 1969 & 919 & MARPOL 1973 \\
Othello & Sweden & 1970 & 483 & MARPOL 1973 \\
Sea Star & Oman & 1972 & 840 & MARPOL 1973 \\
Amoco Cadiz & France & 1978 & 1,600 & MARPOL 1978 \\
Exxon Valdez & Alaska, USA & 1989 & 240 & OPA 1990 \\
American Trader & California, USA & 1990 & 300 & OPA 1990 \\
Erika & France & 1999 & 250 & ERIKA 1 and 2 \\
Prestige & Spain & 2002 & $150-200$ & ERIKA amendments \\
\hline
\end{tabular}

\subsubsection{US regulations}

The pre-1990 relevant legislation regarding the control of commercial shipping vessels include the Federal Water Pollution Control Act of 1972 (FWPCA) and the Comprehensive Environmental Response, Compensation, and Liability Act (CERCLA), 
the Ports and Waterways Safety Act of 1972, and its amendment by the Port and Tanker Safety Act of 1978. Under these acts and the Act to Prevent Pollution From Ships (the US ratification of the International Convention for the Prevention of Pollution from Ships 1973, as amended 1978 (MARPOL 73/78)), the Coast Guard was given authority over waterfront activities and vessel inspections. ${ }^{4}$

Following the Exxon-Valdez incident the Oil Pollution Act was enacted in 1990. It mandates new construction requirements, operational changes, response planning, licensing and manning specifications, and increased liability limits. The most important feature for the issue at hand is the requirement for new tankers to be of double hull construction. Additionally, this provision mandated that existing single hull tank vessels be retrofitted with a double hull or be phased out of operation by 2015 (Section 4115 of OPA 90 - 46 USC 3703a(a)). OPA has a provision for reconsideration of alternative equivalent designs given that the US Coast Guard (USCG) finds them equivalent. Indeed, three reports examined the comparative effectiveness of other designs without changing USCG's recommendation. Another legislative set that plays a significant role in the evolvement of the internal tanker market is the Merchant Marine Act of the 1920 . In Section 27, known as the Jones Act, the cabotage policy mandates ships that connect national US ports be registered in the USA, owned by US citizen companies, and built in the USA. The latter requirement aimed to vitalise the US shipyards but it acts as another deterrent to fleet renewal in the USA. The reason for that is the cost differential between the US built ships and those of the same class found in the international market, which are significantly cheaper. An array of subsidy programs has been set to partially counteract this which exacerbates, from an economic viewpoint, the overall societal deadweight loss from adopting the policy in the USA.

\subsubsection{EU and International Maritime Organisation (IMO) regulations}

IMO regulations are significantly affected by the regulatory activity in the USA and EU. In some cases they may precede and in others follow corresponding legislation in those countries. This happens firstly because they have significant power within the organisation and secondly since their territories' ports are the biggest import ports worldwide. Unilateral action from those countries (without IMO ratification) is generally avoided because it would exacerbate the use of sub-standard vessels in less stringent, developing world markets. In the case of double hull legislation the EU has ratified the equivalent IMO regulations altering the phase-out dates for the old single-hull vessels after the Prestige incident. For this reason only the IMO regulation is presented here. The International Convention for the Prevention of Pollution from Ships, 1973 and the related Protocol of 1978 are known as MARPOL 73/78. The amendments to the MARPOL 73/78 Convention adopted by the IMO on 6 March 1992 impose double hull or equivalent design requirements for oil tankers delivered on or after 6 July 1996. Secondly, they adopt a phasing-out scheme for single hull oil tankers delivered before that date practically setting an age limit for these vessels to 25 years or being retrofitted with double hull. The EU has ratified the treaty with Regulation (EC) No 417/2002. ${ }^{5}$

The major difference compared with the US regulation is in the addition of 'equivalent' referring to the designs accepted that gives some flexibility to the regulation. On the other hand, since IMO regulations are based on voluntary acceptance by countries and the only available enforcement method is denying entry to non-compliant ships, effectively the international shipping industry is forced to be compliant with the more 
specific US regulation that mandates double hull vessels, at least if it wants to service the largest world economy.

\subsubsection{Liability and taking}

Unfortunately, this regional type enforcement does not seal the participating countries since vessels can still compromise coastal environment on international waters. For this reason the international liability issues are significant. OPA and MARPOL specify the liability limits of the captain, owner, manufacturer, and consignee. Other important issues include the insurance determination and the compensatory and punitive damages awarded by courts in case of accidents. Finally a relevant issue, specific to the US legislation that was raised but has yet to be pursued in its fullest is whether the phase-out of single hull vessels constitutes legal taking. One relevant case is the Maritrans, Inc. vs. USA brought before the US Court of Federal Claims. There, the owner of a fleet of domestic barges with a carrying capacity of 4.3 million barrels of oil brought an action in the seeking compensation from the US government for what it alleged was a regulatory taking. Legally no taking occurred and the court dismissed the case as untimely, since the plaintiff had taken no damaging action at the time of the trial, and not because it found that no taking could take place in the future (Cicala, 2000). ${ }^{6}$ The question that is ultimately posed by this and similar cases is who pays the cost of premature fleet turnover. The next section gives more detail on both the technological and economic aspects of the problem that induce uncertainty.

\subsection{Technological adequacy and economic impact}

The technology forcing potential of the US regulations is limited, as it prescribes a single technological solution rather than a performance based standard towards which several designs can be tried and tested. The nature of the policy is technical and the consequences are uncertain, especially from an economic point of view. Before proceeding with the presentation of the model, we briefly discuss the economic impact of the technological aspects of the policy, which is essential for a realistic interpretation of the structural parameters of the model, presented in the next section.

After a presentation of the shipping industry and the regulations concerning the double-hull phase in policy, in this subsection we discuss the technology itself and the reasons that create uncertainty regarding its effectiveness. Although it is undisputed that in the short-term the double hull has positive effects on reducing accidental oil spillage, we argue that the associated technological drawbacks induce significant uncertainty on the economic consequences of the policy and the organisational impact, due to the foregone option to wait until utilising a more cost efficient technology. The reduction of the probability of accidents is sub-optimal, once evaluated within a real options welfare maximising framework, where there is value in waiting.

The double hull design is an incremental development over single hull and certainly not a disruptive technology. It is based on a technical rationale and follows the dominant ship building philosophy, by incorporating the second hull as redundant safety feature. The obvious advantage of the design is the ability to withstand low and some medium force collisions and groundings without oil spill. An additional feature that makes it attractive is the option of putting the pipelines and equipment outside the tank leaving an easier to clean tank surface. The primary disadvantages are: increased construction costs, 
increased maintenance costs and importantly increased difficulty in monitoring and cleaning the surfaces between hulls and finally reduced useful volume for a given vessel size that eventually increases. It is estimated that the capital cost of a double-hull tanker is $9 \%-17 \%$ higher than that of a corresponding single-hull tanker, and operating and maintenance costs are from 5\% to 13\% higher (National Academy Press, 1998). ${ }^{7}$

Some less obvious disadvantages that may compromise the aim of the technology as pollution prevention method and introduce risks regarding its effectiveness are the following:

- The structure of the vessel is becoming significantly more rigid than single hull - for Very Large Crude Carriers. This results in great strains of the structure during heavy seas, which may lead to failure by metal fatigue in less than the life-time of the vessel. This hypothesis has not been tested, since double-hulls have not been used extensively prior the 1990 . The potential reduced life span of the vessel will eventually result in higher costs for the transportation of oil. Furthermore, the lack of empirical testing of these new structures highlights the value of waiting and acquiring additional information, before imposing the policy, especially when the risks (uncertainty) are high. This is a technical argument which highlights the significant level of the long term effects of the policy. Uncertainty is the reason for assigning value to the option of waiting, before adopting the policy.

- Inspections and maintenance of the inner shell becomes (very) difficult with current visual inspection methods, which may induce increased maintenance and repair costs. This may have indirect social costs by increasing the transportation rates in the long-run.

- If a tank leak exists and remains unnoticed or neglected, corrosive chemicals may accumulate in the cofferdam (the space between the two hulls). Additionally, explosive mix of fumes may accumulate in it if no provisions are taken to mitigate this.

- In high impact collisions the energy of a crash will not be absorbed by the first hull and may lead to a breach of the second too resulting in oil spill that may prove more difficult to contain on the spot.

- In cases of grounding, salvage becomes harder because even if the second hull does not fracture, water that fills the cofferdam reduces ship buoyancy and attaches it to the sea bottom. This may also result in instability, depending on the design.

- Some of the current double-hull designs incorporate non-watertight bulkheads in the bow and stern of the ship that may prove a sort of an Achilles heel in case of damage.

All the above highlight the uncertainties as a result of the introduction of a mandatory and irreversible policy, which has not been extensively tested. Despite these possible drawbacks, the US Coast Guard taking into account a number of comparative reports with alternative designs, retained their initial recommendation. Their interpretation of the Congressional intent is that the double hull requirements were mandated to prevent, as far as practicable, any spills from occurring in US waters, i.e., lowest probability of any oil being spilled. In his testimony to the House of Representatives, Rear Admiral Notch stated: 
"the double hull was unmatched in preventing the majority of oil spills when compared to the proposed alternatives. None of those alternatives or the alternatives evaluated since can match the superior performance of the double hull regarding the key performance measure of probability of zero oil outflows for both collisions and groundings."

On the other hand, he also quotes the result of the three reports used by the Coast Guard to evaluate the designs that "the double hull [...] was most effective in low-energy casualties, while the mid-deck design was most effective in high-energy casualties".

In support of the Coast Guard's recommendation two facts are mentioned:

- in 15 accidents involving double hulls from 1990 to 1999 no oil spilled

- oil spill statistics show a significant reduction in the amount of oil spilled and accidents in the US post-OPA ${ }^{8}$.

The first fact does not imply that double hull accidents are non-existent; the latest incident involving a double-hull tanker that resulted in 764.000 gallons of oil spilled near the coasts of Denmark in 2001 or the uniform expert acknowledgment that a double-hull in Exxon Valdez incident would only have reduced the amount of oil-spilled by $40 \%-60 \%{ }^{9}$ can easily prove the opposite. The second fact cannot be supported on double hull legislation since the fleet turnover is much too slow but possibly on the other measures. As the NAS report states "it is clear that the reasons in the improvement of the oil spill picture since 1990 cannot be attributed to the implementation of section 4115 ". ${ }^{10}$

Having analysed the uncertainties regarding the effectiveness of the policy we now focus on adoption costs. From an economic point of view the double-hull phase-in increases both maintenance and construction costs of vessels. Taking into account the highly competitive market structure of the industry, it can be expected that unless stricter enforcement methods are put into place many ship owners may choose to omit vital but costly repairs in the inside, difficult to reach inner hull, which might induce high levels of uncertainty regarding the long term technical and economic performance of the policy. Furthermore, the burden of frequent and more difficult inspections is expected to add to the overall implementation costs. The intense competition in the tanker industry and the new building industry has lead to the deterioration of tanker new building standards (Devanney and Kennedy, 2003) in some cases to imprudent levels. The severe competition in the new building industry is attributed either to subsidisations (Strandenes, 2002) or to sub-optimal economic behaviour, due to over capacity in the industry (Dikos, 2004b). In order to survive competition the yards have been constantly searching for ways to "shave the rules". This tendency towards deteriorated quality may be expedited, by the technical uncertainty induced by the new structure and the absence of meaningful guarantees, which raise the threat of relaxation of the rules. This potential risk regarding the economic life and quality of the vessels has a profound impact on the range of social costs.

Even without taking into account these increases in cost and the potential uncertainty in the response of shipyards and investors, a study of the US situation conducted in 1996 has estimated using traditional benefit-cost analysis that even if all oil spills caused by tanker accidents were prevented by the Oil Pollution Act, the costs of its implementation to society would still surpass the benefits (Brown and Savage, 1996). The study estimates that an increase of 14 cents per barrel or a $0.7 \%$ increase in the end oil price and concludes with a benefit-cost ratio of $46 \%$ for the most favourable case (total oil spill 
reduction). Although, care has been taken to put ample monetary value to the environmental damages the questionable valuation of non-monetary effects, the fact that all value streams are discounted (by 7\%) and finally the fact that construction costs reflect the non-competitive costs of US built ships indicate that this number should not be taken into account at face value. However it provides preliminary evidence that the mistakes by foregoing the associated option value of waiting and acquiring information may have led to a significant sub-optimal timing of this policy. As presented in detail in Section 3, in applying our proposed evaluation framework, we use the assumptions and monetisation framework presented by Brown and Savage (1996).

The above reasoning identifies the main sources behind the technological and economic uncertainty of the policy. It will be for this uncertainty, that there is value in the option of waiting before adopting an irreversible policy. The value of this option becomes higher when taking into account, that the adoption of the policy is a barrier for research and innovation, towards a solution to the problem at hand.

\section{Framing the problem: application of real options theory to environmental policy}

The double-hull policy has induced scepticism in the maritime industry. Despite minimisation of the probability of oil spill in the long term, there are major economic and technical aspects of the policy, which create uncertainty regarding its effectiveness.

It is beyond the scope of this paper to introduce alternative technological and organisational solutions in order to pursue higher safety margins for the marine environment. This task has been undertaken by Sgouridis (2002) and is a topic of debate for the society of marine engineers and the International Maritime Organisation. For an excellent review of maritime safety economics the reader should consult the influential paper by Ma (2002).

Following Hausman and Meyer (2002) we introduce a framework for analysing the mistakes by foregoing the option to wait due to uncertainty arising from the technical rigidities, irreversible social costs and deficiencies discussed in the previous subsection. In the optimal timing framework introduced by Pindyck (2002) it is demonstrated how large the mistakes can be by foregoing the option to wait.

From a technical point of view the phasing-in of double hull vessels is a mandated technological shift that stifles innovative approaches to the design of oil carriers, since it gives no incentives for their creation. Furthermore, once adopted there is no exit strategy, which makes the cost of adopting this policy completely sunk. Overall, the main source of uncertainty is due to the lack of knowledge regarding its consequences. It is very difficult to accurately quantify the effects on the environment and society. At the same time, it may not even ensure a higher long-term safety margin than the design it replaces, if the status quo of the oil shipping industry remains dominant: i.e., the maintenance, ownership status, and incident record of vessels remain obscure to the inspection authorities of the port countries and the strains on seamen are not effectively reduced so that the number of accidents due to human error (the leading cause of oil-spill accidents) are reduced. Furthermore, unfavourable economic conditions and increased construction costs may result negatively on the quality of new vessels which increases technical uncertainty on the long term effectiveness of the policy. On the cost side, this type of ship is more expensive in terms of both capital and operating costs, which results in 
significant and irreversible adoption costs. The three factors discussed, namely the increased adoption costs, the irreversible nature of the policy switching costs and uncertainty on the effectiveness of the policy are not taken into consideration in the static cost-benefit analysis framework. We now introduce the basic real options model for analysing the optimal timing of environmental policies and the parameters of the model as matched to the costs, benefits and risks of the policy. Despite its simplicity it accommodates both the effects of the sunk costs imposed on society, as well as the negative opportunity costs by foregoing the option to wait. The model allows the assessment of the economic consequences by foregoing uncertainty, irreversibility and sunk costs in a quantitative framework.

\subsection{The real options model}

Within the framework of traditional cost-benefit analysis of environmental policy, the problem boils down to whether or not a policy should be adopted. Under uncertainty and irreversibility the real problem is basically when a policy should be adopted. Therefore, it is a question of optimal timing, which corresponds to an optimal stopping rule.

For our purposes we apply a model which was introduced by Pindyck (2002), which has the following form:

$$
\frac{\mathrm{d} M}{\mathrm{~d} t}=\beta E(t)-\delta M(t)
$$

where

$M_{t}$ : $\quad$ Oil emitted to the sea, due to oil spill accidents

$E_{t}$ : $\quad$ Flow variable that controls $M_{t}$

$\delta: \quad$ Natural rate at which oil dissipates over time.

We assume that the flow of social cost (negative benefit) associated with $M_{t}$ can be specified by a function $B\left(M_{t} ; \theta_{t}\right)$, which is the social norm of the policy maker, where $\theta_{t}$ is the elasticity of the social cost with respect to the pollutant stock, or a stochastic time-varying shift, which reflects changes in technology. For example $\mu t$ stands for the effectiveness of the policy or it may reflect a new technology that reduces oil spills after an accident. As the effects of the technology are uncertain, it is normal to assume that this parameter evolves stochastically. $B$ is assumed linear in $M$ and the higher the uncertainty of $\mu$ the higher its contribution to the negative benefit:

$$
B\left(M_{t}, \theta_{t}\right)=-M_{t}, \theta_{t} .
$$

We adopt the assumption by Pindyck (2002, pp.4, 5): Until a policy is adopted $E_{t}$ stays constant at the initial level $E_{0}$, and policy adoption implies a once and for all reduction to a new permanent level $E_{1}$, with $0<E_{1}<E_{0}$. Finally, we assume that the cost of adopting this policy is completely sunk (which is a very realistic assumption in our case) and its present value at the time of adoption $\left(K\left(E_{1}\right)\right)$ is a function of the size of the emission reduction. The objective is to maximise the net present value of the social cost objective function: 


$$
W=\varepsilon_{0} \int_{0}^{\infty}\left(\theta_{t} \times M_{t} \times e^{-r t} \mathrm{~d} t\right)-\varepsilon_{0} K\left(E_{1}\right) \times e^{-r t}
$$

where

T: $\quad$ Uunknown time

$E_{0}-E_{1}$ : Achieved reduction of oil spilled

$\varepsilon_{0}$ : $\quad$ Expectation at $t=0$ with respect of evolution of $M_{t}$

$r$ : Discount rate

$\theta_{t}$ : $\quad$ Stochastic time varying shift, which reflects the changes in technology.

Here $T$ is the unknown time that the policy is adopted, $E_{0}-E_{1}$ the achieved reduction in oil spilled and $E_{0}$ stands for the expectation at time $t=0$ with respect to the evolution of $M_{t}$ and $r$ is the discount rate. Assuming that the adoption of the policy, reduces emissions from $E_{0}$ to zero, a binomial ('two-state world') specification over the evolution of $\theta_{t}$ yields a closed form solution. Pindyck (2002, pp.4-8) demonstrates that the critical value for technology, that triggers the enforcement of the policy is:

$$
\hat{\theta}_{T}=\frac{r(r+\delta) K}{\beta \times E_{0}} .
$$

Below (Table 2) we provide a structural interpretation into the parameters of the optimal environmental policy problem for the case of the double hull phase-in question.

Table 2 Parameters of the model

\begin{tabular}{lcl}
\hline Parameter name & Symbol & Value \\
\hline Discount rate & $r$ & 0.04 \\
Oil decay rate & $\delta$ & 0.01 \\
Absorption factor & $\beta$ & 0.95 \\
PV of cost of policy adoption & $K$ & $\$ 25$ billion \\
Emission rate & $E_{0}$ & 8135 ton/year \\
Current social cost & $\theta_{0}$ & 52085 USD/ton/year \\
Future social cost (low) & $\theta_{d}$ & 68400 USD/ton/year \\
Future social cost (high) & $\theta_{u}$ & 35771 USD/ton/year \\
Fixed delay time & $T$ & 5 \\
\hline
\end{tabular}

Before extending our model in order to incorporate more salient characteristics of the problem at hand, we give a structural interpretation into the parameters of the optimal environmental policy problem for the case of the double hull phase-in question. Following Brown and Savage (1996, p.171) we adopt an emission rate $E_{0}=8135$ tons/year and a range between 35771-68400 USD/tons/year for the social cost of each ton spilled and a present value of the cost of policy adoption equal to 9 billion USD. ${ }^{11}$ Realistic assumptions regarding the impact of the technological and economic uncertainty within the optimal timing problem framework allow a direct assessment of 
the induced losses from foregoing the real options and the economic nature of the problem.

For the above inputs $\theta_{t}=2329 \mathrm{USD} /$ ton/year which indicates immediate policy adoption as this value is far below the lowest bound for the future social cost. However, there is significant ambiguity in determining appropriate bounds for the the level of social costs, as these are heavily biased due to legal costs. Furthermore, the binomial specification of risk does not fully correspond to the characteristics of the problem at hand. Although this model is very restrictive as it assumes only two states of the world for social cost, it is useful in introducing the basic principles of posing the question of policy adoption as an optimal timing problem. Following Pindyck (2002) we generalise the model and assume that both $\theta_{t}$ and $M_{t}$ evolve stochastically:

$$
\begin{aligned}
& \mathrm{d} \theta_{t}=\alpha \theta_{t} \mathrm{~d} t+\sigma_{1} \theta_{t} \mathrm{dz}_{1} . \\
& \mathrm{d} M=(\beta E(t)-\delta M(t)) \mathrm{d} t+\sigma_{2} \mathrm{dz} .
\end{aligned}
$$

Pindyck (2002, pp.16-21) defines a quadratic social benefit function and assumes that the policy reduces emissions from $E_{0}$ to zero for an adoption cost $K=k \times E_{0}$. Pindyck (2002, p.17) demonstrates that the rule for policy adoption that maximises the net present value function of equation (3) subject to the evolution of equations (5) and (6) is a critical activation ratio between the present value of the gains from adopting the policy and the cost of adoption $K$. The rule is given by:

$$
\frac{P V}{K}=\frac{\left(\frac{2 \beta E_{0}^{2} \theta}{(r-\alpha)^{3}}+\frac{2 \beta E_{0} \theta M}{(r-\alpha)^{3}}\right)}{K}
$$

This ratio is extremely useful for policy evaluation: Instead of calculating the induced real options or solving the differential equations we may divide the post adoption net present value benefits (without any calculations for the value of waiting) with the adoption costs and check if this ratio is higher than the one derived in equation (7). Under a traditional NPV rule, adoption would occur when this radio exceeds one. As $\sigma_{1}, \sigma_{2}$ approach 0 the ratio converges to one (traditional cost benefit analysis). For small values of the level of the current pollutant stock $M$ the critical threshold $\theta$ becomes large and therefore this ratio becomes much higher than one. For the structural parameters introduced previously the appropriate $P V / \mathrm{K}$ ratio ranges from 2.59 (for $M=8135$ ) to 10.18 (for $M=150000$ ). The ratio is robust to $\sigma_{1}, \sigma_{2}$ which are the most difficult to assess.

Brown and Savage (1996) argue that the present value benefits of the net present value are under half of the costs, even under the most favourable assumptions for adoption. Even if this is not the case, under uncertainty and irreversibility the appropriate policy rule in equation (7) highlights the fact that in order to exercise the option to wait (wait and collect more information or examine alternative solutions) the gains have to be at least twice as much as benefits.

The implications from the real options model are clear. The norm for policy makers has been the minimisation of the probability of the accident, mainly due the large collateral social costs. In an economic framework and using the appropriate norm under uncertainty and irreversibility the policy may be sub-optimal. So have policy makers been wrong? Has the double-hull policy been adopted due to pressure from society and media? As explained in the influential paper by Ma (2002) maritime transport related 
problems are mainly related to accidents. The discussed model in this section are approximations to a continuous pollutant stock, which is more relevant to emissions. In the next section we extend Pindyck's (2002) model and introduce a Poisson jump that corresponds to irregular changes due to accidents.

\section{Accounting for extreme events: a model with jumps}

We follow Pindyck (2000) and assume that the only source of uncertainty is ecological (due to accidents). Although it is a simplification to exclude policy uncertainty this is the only way to obtain a closed form solution with jumps. However, a numerical solution may be obtained with technological uncertainty. As large disasters occur in a random poisson manner (Brown and Savage, 1996), we assume that the pollutant stock, follows the standard Gaussian mean reverting process augmented by jumps:

We assume that the pollutant stock, follows the standard Gaussian mean reverting process augmented by jumps:

$$
\mathrm{d} M=(\beta E(t)-\delta M(t)) \mathrm{d} t+\sigma \mathrm{d} z+\mu \mathrm{dq} .
$$

The jump part that captures random discrete accidents is assumed to follow a Poisson process with intensity $\lambda$ (the probability of a jump/accident each year) and positive jump size $\mu$, which assumed constant. Following Hanson (2006) and Ito modified stochastic rule for Poisson jumps we get the following result for the policy function at the no adoption region:

$$
\mathrm{d} J=J_{t} \mathrm{~d} t+[b E(t)-\delta M] J_{M} \mathrm{~d} t+J_{M} \times \sigma \mathrm{d} z+1 / 2 \sigma^{2} J_{M M} \mathrm{~d} t+[J(M+\mu)-J) \mathrm{d} q .
$$

We assume that the $E(t)$ is independent of time and for the reasons explained by Pindyck $\left(2000\right.$, pp.253, 254) the social cost is convex in $M$ such that $B(M ; \theta)=-\theta M^{2}$. We apply the optimality condition (Dixit and Pindyck, 1994) and get the following Bellman equation for the region without policy adoption:

$$
[\beta E-\delta M] J_{M}+1 / 2 \sigma^{2} J_{M M} \mathrm{~d} t+[J(M+\mu)-J] \lambda-r J=\theta M^{2} .
$$

In order to get a closed form solution we assume that once adopted $E=0, \lambda=0$ and the cost of the policy adoption is $\mathrm{K}$. Then the Bellman equation once the policy is given by:

$$
\frac{1}{2} \sigma^{2} J_{M M}^{\prime}-r J^{\prime}=\theta M^{2}
$$

The value functions in equations (10) and (11) must satisfy the standard boundary conditions at the critical value $M^{*}$, where the policy is adopted:

$$
\begin{aligned}
& J_{M}^{\prime}(0)=0 \\
& J\left(M^{*}\right)=J^{\prime}\left(M^{*}\right)-K . \\
& J_{M}\left(M^{*}\right)=J^{\prime}{ }_{M}\left(M^{*}\right)
\end{aligned}
$$

Using standard calculus we derive the closed form for the critical value that triggers policy adoption: 


$$
M^{*}=\frac{1}{k_{1}}-\frac{1}{r}[\beta E+\lambda \mu]-\frac{\theta \lambda \mu^{2}}{2[\beta E+\lambda \mu]} .
$$

$k_{1}$ satisfies the characteristic equation:

$$
\frac{1}{2} \sigma^{2} k^{2}+\beta E k-(\lambda+r)+\lambda e^{k \mu}=0 .
$$

For $\lambda=0$ (which implies no accidents) the formula collapses to that of Pindyck (2000, p.255). On the one hand stochastic fluctuations create an incentive to delay policy adoption, whereas on the other hand the presence of jumps reduce the critical value of policy adoption! In this case the ratio between the present value of the gains from adopting the policy and the cost of adoption $K$ is given by the formula:

$$
\frac{P V}{K}=1+\frac{2 \theta(\beta E+\lambda \mu)}{K k_{1} r^{2}}
$$

As $k_{1}$ is a decreasing function of $\lambda$ the contribution of $\lambda$ on the $P V / K$ ratio depends on the structural parameters. For our case the ratio is found equal to 2.16 , which is fairly closer to the cost-benefit result. For all the parameters we tried for the jump size and jump probability this ratio appeared significantly lower compared to the previous one.

Increased economic and technical uncertainty, the large sunk costs of adopting the policy and irreversibility of the technology, as you cannot remove it once adopted, place significant value in the option to wait before adopting the policy. This result is well highlighted in the model of Pindyck (2002) on the optimal timing of environmental policy. However, extending the model in order to account for the presence of extreme events (which is the case in this industry) reduces the value of waiting. The policy implications are two-fold: Firstly, the probability of extreme events forces immediate intervention and secondly, policy makers have to be meticulous in choosing the appropriate framework and model specification. Within the context of the question at hand, the presence of jumps indicates that policy adoption has been in the right direction, as the foregone value of waiting for information and innovation may be offset by hedging against the probability of extreme events. Whether this specific policy is optimal or not, this is left as a topic for further research. Within the proposed model, numerical solutions of a more complicated jump-diffusion model may reveal the affirmative answer to this question.

\section{Discussion of policy recommendations and conclusions}

Oil tanker accidents have lead to catastrophic environmental pollution of marine and coastal environments. A continuation of a trend for such incidents may cause difficulty in predicting impacts on the overall oceanic environment. Although the oil shipping industry achieves high safety margins, the risks remaining are still not acceptable by society because of the catastrophic consequences, resembling in some ways the picture presented by the nuclear energy or biotechnology industries. This has increased the pressure by society on politicians to take some action and has directed towards the immediate adoption of an uncertain policy. 
Having posed the problem in an optimal timing framework we have demonstrated the importance of taking into account sunk costs and irreversibility. Especially in the tanker industry, the uncertainty regarding the long-term effects of the double-hull policy and the the interrelated social costs, increase significantly the value of the foregone knowledge, information and the associated option to wait. The irreversible nature of the policy results in losing the opportunity to foster designs that could be more effective, less costly for the society and lead to creative preventive steps.

Using the economic framework of the optimal timing of environmental policy we propose a framework for estimating the mistakes by foregoing the associated option value of waiting. The policy implication to regulators is clear: The higher the lost option value by the adoption of the policy, the more the legal and organisational strategies that should be used to accomplish the innovation target in conjunction with the drivers and incentives in the industry. Finally, the sunk nature of the policy, does not leave an option to policy makers, to adjust the rules according to the acquired information on the long term performance of double hull vessels. Motivated by the discontinuity of emissions in this industry, due to their accidental nature, we extend the standard model for the optimal timing of environmental policy (Pindyck, 2002), in order to accommodate irregular changes. Neglecting the occurrence of jumps can be misleading as policy should then be undertaken earlier. This demonstrates that regulators should be particularly cautious when adopting their model, as the implied policy recommendations are very sensitive to the specification of the underlying process. Finally, in order to take into account the uncertainty regarding the range of the parameters of the problem at hand a robust control approach seems promising.

The double-hull phase-in problem provides a unique framework for an empirical test of the impact of policy uncertainty on investment. As discussed by Dixit and Pindyck (1994, p.303) governments create uncertainty through the process of policy change, which is particularly relevant in the tanker industry and this induces a real option of waiting. Empirical research should focus on the response of the market to a potential new regulation, regarding the demand for new vessels and the effects of policy uncertainty on tanker investment decisions. If markets are efficient and 'always right' it is of profound interest to understand their response to the new policy.

\section{Acknowledgments}

Sgouris P. Sgouridis is grateful to the A. Onassis Public Benefit Foundation for their financial support. We would also like to thank seminar participants at the Massachusetts Institute of Technology and the Erasmus University Rotterdam for useful comments and suggestions. The usual disclaimer applies.

\section{References}

Brown, R.S. and Savage, I. (1996) 'The economics of double-hulled tankers', Maritime Policy and Management, Vol. 23, No. 2, pp.167-175.

Cicala, C. (2000) The Double Hull Requirement of the Oil Pollution Act of 1990: Does It Constitute a Regulatory Taking?, 24 Tul. Mar. L.J. 877.

Devanney, J. and Kennedy, M. (2003) The Down Ratchet, http://www.c4tx.org/ ctx/pub/downratchet/index.html, Center for Tankship Excellence. 
Dikos, G. (2004a) Decisionmetrics: A Micro Econometric Analysis of Shipping Investment Decisions, Unpublished Doctoral Thesis, Massachusetts Institute of Technology, Cambridge MA.

Dikos, G. (2004b) 'New building prices: demand inelastic or perfectly competitive?', Maritime Economics and Logistics, Vol. 6, No. 4, pp.312-321.

Dixit, A.K. and Pindyck, R.S. (1994) Investment under Uncertainty, 2nd ed., Princeton University Press, Princeton.

Gold, E. (1991) 'Marine pollution liability after exxon valdez: the US all or nothing lottery!', Journal of Maritime Law and Commerce, Vol. 22, No. 3, pp.423-444.

Hanson, F. (2006) Applied Stochastic Processes and Control for Jump-Diffusions: Modeling, Analysis and Computation, Submitted for review to SIAM Books: Advances in Design and Control Series.

Hausman, J. and Meyers, S. (2002) 'Regulating the United States railroads: the effects of sunk costs and asymmetric risk', Journal of Regulatory Economics, Vol. 22, No. 3, pp.287-310.

Ma, S. (2002) Economics of Maritime Safety and Environment Regulations, Handbook of Maritime Economics and Business, LLP Press, London.

McDonald, R. and Siegel, D. (1984) 'The value of waiting to invest', Q.J.E., Vol. 101, No. 4, pp.707-728.

National Academy Press (1998) Double-Hull Tanker Legislation: An Assessment of the Oil Pollution Act of 1990, National Academy Press, Washington DC.

National Research Council (1985) Oil in the Sea, National Academy Press, Washington DC.

Pindyck, R.S. (2000) 'Irreversibilities and the timing of environmental policy', Resource and Energy Economics, Vol. 22, pp.233-259.

Pindyck, R.S. (2002) 'Optimal timing problems in environmental economics', Journal of Economic Dyanmics and Control, Vol. 26, pp.1677-1697.

Sgouridis, S.P. (2002) Double-Hull Tanker Phase In - Is it the Best Way to Prevent Maritime Pollution?, Technology Law and Public Policy Working Paper, Massachusetts Institute of Technology, Cambridge.

Strandenes, S.P. (2002) The Economics of the Market for Ships, Handbook of Maritime Economics and Business, LLP Press, London.

Wang, T. and deNeufville, R. (2005) Real Options 'in' Projects, 9th Real Options International Conference, Paris, France.

\section{Notes}

${ }^{1}$ Usual sheet thickness is $35 \mathrm{~mm}$ or with the use of high tensile steel, $25 \mathrm{~mm}$.

${ }^{2}$ Both US and international regulations allow for the potential use of 'equivalent' tanker designs; however, since the USA has accepted no other design as 'equivalent', no other design than double hull is being used to meet the regulations.

${ }^{3} \mathrm{~A}$ comprehensive list of major oil spill incidents with greater detail in recent years can be found in http://www.marinergroup.com/oil-spill-history.htm

${ }^{4}$ More information in: US coast guard, statement of rear admiral Robert, C. north on double hull requirements for tank vessels, subcommittee on coast guard and maritime transportation, US house of representatives, 1999. Available online from http//www/house/gov/transportation/ cgmt/hearing/06-29-99//north.html

${ }^{5} \mathrm{~A}$ good outline of the relevant MARPOL regulations and EU ratification is provided in the Official Journal of The European Communities, "Regulation (Ec) No. 417/2002 of the European Parliament" available online from http:/europa.eu.int/eurlex/pri/en/oj/dat/ 2002/1 64/1 6420020307 en00010005.pdf

${ }^{6}$ More details in: Criston Cicala (2000). 
${ }^{7}$ See the Executive summary pp.6. Available online from: http://www.nap.edu/books/ 0309063701/html/index.html

${ }^{8 *}$ The average number of oil spills over 10,000 gallons in the USA has dropped by almost $50 \%$ from pre-1991 levels. In addition, the average annual amount of oil spilled in the USA from 1986-1990, before OPA 90 was enacted, was 6.2 gallons per million gallons of oil shipped. PostOPA 90 figures (1991-1995) show this average has dropped to 1.4 gallons per million gallons of oil shipped".

${ }^{9}$ Indicatively i) MIT Professor H.S. Marcus in "Why professors should be teaching for understanding on two levels," says:

"One might consider the answers to the following questions: Will double hulls on tankers prevent an oil spill from an Exxon Valdez type accident? Are double hulls that best design to prevent or minimise oil spills in an Exxon Valdez, type oil spill? Will new double hull tankers always spill less in accidents than the single hull tankers they replace? The answers to all three questions are 'No'."

available online in http://www.sbaer.uca.edu/Research/1997/WDSI/97wds346.txt and ii) the USCG experts cited in John Keeble, "Out of the channel: The exxon valdez oil spill in Prince William sound," University of Washington Press , 1999.

${ }^{10}$ NAS Double Hull Assessment, see note 8, p.20 (note omitted).

${ }^{11}$ Other sources suggest much higher policy adoption costs (http://www.nap.edu/readingroom/ books/tanker).

\section{Bibliography}

Bertola, G. and Caballero, R.J. (1990) 'Kinked adjustment costs and aggregate dynamics', in Blanchard, O. and Fisher, S. (Eds.): NBER Macroeconomics Annual 1990, MIT Press, Cambridge MA, Vol. 23, pp.237-295.

Blanchard, O. and Fisher, S. (1998) Lectures on Macroeconomics, MIT Press, Cambridge MA.

Grammenos, C. (Ed.) (2002) The Handbook of Maritime Economics and Business, LLP Press, London.

Hausman, J. (1999) in Alleman, J. and Noam, E. (Eds.): The Effect of Sunk Costs in Telecommunications Regulation, The New Investment Theory of Real Options and its Implications for Telecommunications Economics, Publisher Springer, USA, p.24.

Stopford, M. (1991) Maritime Economics, Routledge Press, London.

Zannetos, Z. (1966) The Theory of Oil Tanker Ship Rate, MIT Press, Cambridge MA. 